\title{
A Radioimmunoassay Method for Determination of Fish Plasma Insulin*1
}

\author{
Masayuki FURUICHI*2, Yoshihiro NAKAMURA ${ }^{* 3}$, and Yasuo YONE ${ }^{* 2}$ \\ (Received May 20, 1980)
}

\begin{abstract}
The present study was undertaken to clarify whether the radioimmunoassay for the determination of plasma insulin in humans is applicable to quantify that of the fishes, and to improve the assay method. In experiments in which ${ }^{125} \mathrm{I}$-skipjack insulin was used as a tracer, human insulin did not react to the anti-skipjack insulin serum, whereas skipjack insulin reacted very strongly. Red sea bream and yellowtail insulins showed a similar reaction to skipjack insulin. It was also found that the fish plasma can be employed as the blood plasma which is added into the assay system of standard skipjack insulin. On the basis of these findings, a modified method was presented to determine the plasma insulin of fishes. Furthermore, when this modified method was used, the $B / T$ ratio of standard skipjack insulin exhibited little deviation at various levels, and also high recovery was obtained for red sea bream insulin. These results indicate that this method can be applied to determine the plasma insulin of fishes.
\end{abstract}

In the previous paper, ${ }^{1)}$ we considered that growth retardation and decreased feed efficiency in the fish resulted from the feeding of high dextrin diets might be due to the low utilization of dextrin absorbed, and that the low capacity of utilization appears to be caused by a low insulin secretion. To confirm this presumption, it is necessary to determine the change of insulin content in blood plasma of fishes after feeding. The determination of fish plasma insulin, however, has not been attempted. On the other hand, since the radioimmunoassay of insulin was established by YALOW and BERSON ${ }^{27}$, various improved methods have been used for the determination of plasma insulin in humans. These methods are classified into a single antibody and a double antibody method. The former is simpler in the assay procedure than the latter, and it seems to be applicable to determine fish plasma insulin. In the present paper, therefore, the applicability of a single antibody method using ethanol precipitation of insulin-antibody complex ${ }^{3 /}$ to determine levels of plasma insulin in fish was examined and modified.

\section{Materials and Methods}

\section{Fish Insulin}

Red sea bream Chrysophrys major, yellowtail Seriola quinqueradiata, and skipjack Katsuwonus pelamis insulins were extracted with acid-acetone from fresh Langerhans islets which were stored in saturated picric acid solution, and then were purified through a Sephadex G-50 column. The potencies of these insulins were $16.3 \mathrm{U} / \mathrm{mg}, 15.6$ $\mathrm{U} / \mathrm{mg}$, and $17.0 \mathrm{U} / \mathrm{mg}$, respectively.

\section{Standard Insulin Solution}

Red sea bream, yellowtail, and skipjack insulins were dissolved in a small quantity of $0.1 \mathrm{~N}$ $\mathrm{HCl}$, and then were diluted with $0.04 \mathrm{M}$ phosphate buffer ( $\mathrm{pH} \mathrm{7.4)}$ to the concentration of $1,000 \mu \mathrm{U} /$ $\mathrm{ml}$, and stored at $-20^{\circ} \mathrm{C}$. To obtain a standard curve, each stock solution was diluted further with veronal buffer $(0.05 \mathrm{M}, \mathrm{pH} 8.6)$ containing $0.9 \% \mathrm{NaCl}$ and $0.1 \%$ bovine albumin and a series of solutions containing $0,3.9,7.8,15.6,31.2,62.5$, and $125 \mu \mathrm{U} / \mathrm{ml}$ were pro ided.

\section{${ }^{125}$ I-labelled Skipjack Insulin}

Skipjack insulin was labelled with ${ }^{125} \mathrm{I}$ by the Dainabot RI Research Institute. The specific ac-

*1 Contribution from Fish. Res. Lab., Kyushu Univ., No. 147. The Utilization of Carbohydrate by FishesII. This work was supported in part by Grant-in-Aid for Encouragement of Young Scientist (Grant No. 776140) from the Ministry of Education, Science and Culture of Japan.

*2 Fish. Res. Lab., Kyushu Univ., Tsuyazaki, Fukuoka 811-33, Japan（古市政幸・米 康夫：九州大学農 学部附属水実験所).

*3 Fukuoka Red Cross Hospital, Minami-ku, Fukuoka 815, Japan (仲村吉弘：褔网赤十字病院). 
Table 1. Radioimmunoassay procedure of fish plasma insulin

\begin{tabular}{|c|c|c|c|}
\hline \multirow{3}{*}{$\begin{array}{l}\text { Test tube } \\
\mid+ \text { Buffer }^{* 1}\end{array}$} & \multirow{3}{*}{$\begin{array}{c}\text { Sample (or } \\
\text { std. ins.) } \\
0.1(\mathrm{~m} l)\end{array}$} & \multicolumn{2}{|c|}{ Blank of } \\
\hline & & sample & std. ins. \\
\hline & & $0.2(\mathrm{~m} l)$ & $0.3(\mathrm{~m} l)$ \\
\hline + Sample (or standard skipjack insulin) & 0.1 & 0.1 & - \\
\hline$+{ }^{125} I$-skipjack insulin & 0.1 & 0.1 & 0.1 \\
\hline + Anti-skipjack insulin serum & 0.1 & - & - \\
\hline \multicolumn{4}{|l|}{ Mix well and incubate at $4^{\circ} \mathrm{C}$ for 72 hours } \\
\hline \multicolumn{4}{|l|}{ Count total radioactivity of mixture $(t)$} \\
\hline+ Buffer $* 1$ (or fish plasma)*2 & 0.1 & 0.1 & 0.1 \\
\hline$+80 \%$ ethanol & 2.5 & 2.5 & 2.5 \\
\hline \multicolumn{4}{|l|}{$\begin{array}{l}\text { Mix well and centrifuge at } 3,000 \mathrm{rpm} \\
\text { for } 15 \text { minutes at } 4^{\circ} \mathrm{C}\end{array}$} \\
\hline \multicolumn{4}{|l|}{ Remove supernatant fluid by decantation } \\
\hline Count radioactivity of precipitate (b) & & & \\
\hline
\end{tabular}

tivity of labelled insulin was $405 \mathrm{mCi} / \mathrm{mg}$. The labelled insulin was purified through the Sephadex G-50 column $(18 \times 250 \mathrm{~mm})$ to remove the rediation-damaged components and noninsulin contaminants. The purified insulin was diluted 1:50 to $1: 100$ with the veronal buffer, and used.

\section{Anti-skipjack Insulin Serum}

Antiserum to skipjack insulin was prepared with guinea pigs by the following method: 0.5 to $1.0 \mathrm{ml}$ of the mixture of skipjack insulin and Freund's complete adjuvant $(1: 1)$ was injected five times to young guinea pigs at intervals of 2 weeks, and $1.0 \mathrm{~m} l$ of the mixture was injected again one month after the fifth injection. The blood was sampled from the heart of guinea pigs ten days after the final injection, and centrifuged at $3,000 \mathrm{rpm}$ for 15 min. Anti-skipjack insulin serum obtained was stored at $-20^{\circ} \mathrm{C}$ and diluted $1: 15,000$ with the veronal buffer when used.

\section{Insulin Assay Procedure}

The radioimmunoassay procdeure of the plasma insulin in fishes is summarized in Table 1. In the assay of standard insulin, $0.1 \mathrm{ml}$ of the veronal buffer, standard skipjack insulin ( 0 to $125 \mu \mathrm{U} / \mathrm{m} l$ ), ${ }^{125}$ I-skipjack insulin, and anti-skipjack insulin serum are pipetted into a small test tube and then mixed throughly. The total radioactivity $(t)$ of the mixture is counted after the $72 \mathrm{~h}$-incubation (antigen-antibody reaction) at $4^{\circ} \mathrm{C}$. Thereafter, $0.1 \mathrm{ml}$ of fish plasma and $2.5 \mathrm{ml}$ of $80 \%$ ethanol are added into the incubated mixture. These are mixed well and centrifuged at 3,000 rpm for $15 \mathrm{~min}$ at $4^{\circ} \mathrm{C}$. The radioactivity (b) of ${ }^{125} \mathrm{I}$ in the pre- cipitate is counted after the removal of the supernatant fiuid by decantation. Then, the $b / t$ ratios $(\%)$ of standard insulin are calculated. A blank test is conducted with the same method as in the assay of standard insulin, except that the veronal buffer is substituted for standard insulin and anti-skipjack insulin serum. The $b / t$ ratios $(\%)$ of the sample and its blank are also assayed and calculated with the same procedure. Duplicate tests must be conducted to obtain the reliable results.

\section{Calculation of Immunoreactive Insulin Content}

By employing the following formula, the correction can be made for the $b / t$ ratio $(\%)$ of standard insulin. Furthermore, the standard curve is drawn by plotting the corrected $B / T$ ratio $(\%)$ and the corresponding concentration of insulin $(\mu \mathrm{U} / \mathrm{m} l)$ on the section paper. The $b / t$ ratio ( $\%$ ) of sample is also corrected by the same formula, and the insulin content $(\mu \mathrm{U} / \mathrm{m} l)$ in a sample which corresponds to the corrected $B / T$ ratio $(\%)$ is read from the standard curve.

$$
B / T(\%)=\frac{I-I_{0} \times 1 / 2}{100-I_{0} \times 1 / 2} \times 100
$$

$I: b / t(\%)$ of standard insulin and sample

$I_{0}: b / t(\%)$ of each blank

\section{Results and Discussion}

Reactions of Skipjack and Human Insulins to Antiskipjack Insulin Serum

If the fish insulin shows the strong crossreaction to human insulin, it can be determined by the 
radioimmunoassay system for human insulin. However, it has been reported that an immunological difference exists between the fish and the mammalian insulins ${ }^{4-7}$. In this experiment in which ${ }^{125}$ I-skipjack insulin was used as a tracer, therefore, the reactions of human and skipjack insulins to the anti-skipjack insulin serum were compared. As shown in Fig. 1, the human insulin did not react to the anti-skipjack insulin

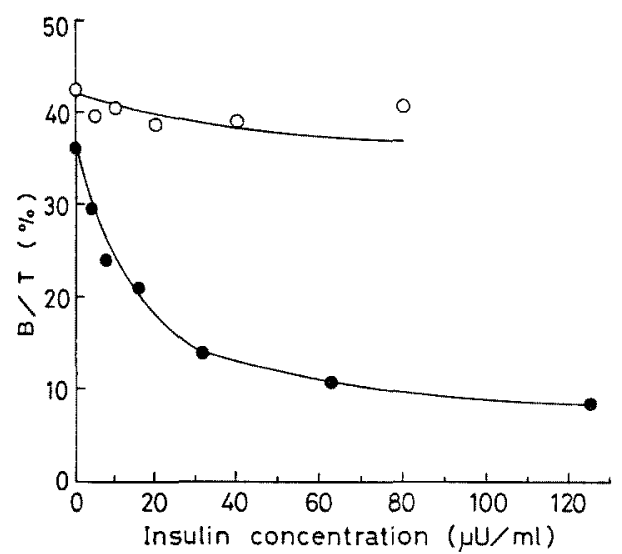

Fig. 1. Change in $B / T$ ratios of human and skipjack insulin levels when anti-skipjack insulin serum was used.

Human insulin, Skipjack insulin.

serum, whereas the skipjack insulin reacted very strongly. Accordingly, the radioimmunoassay system for human insulin can not be applied to the determination of skipjack insulin.
Reactions of Red Sea Bream and Yellowtail Insulins to Anti-skipjack Insulin Serum

In order to confirm whether the assay procedure which is given in Table 1 , is applicable to the determination of plasma insulin in red sea bream and yellowtail, the reactions of these insulins to anti-skipjack insulin serum were compared with that of skipjack insulin. The formers exhibited the similar reaction to skipjack insulin (Tables 2 and 3, Fig. 2). From these findings, it is presumed that the immunological difference is small among these insulins.

Effect of Various Blood Plasmas on Standard Curve of Skipjack Insulin

An experiment was conducted to examine whether the standard curve of skipjack insulin changes by the difference of blood plasma used in the assay system. As shown in Fig. 3, higher standard curves were shown by the use of human plasma than those with fish plasma. On the other hand, comparable curves were obtained with red sea bream, yellowtail, and carp plasmas. It is supposed that high standard curves resulting from human plasma were caused by a large amount of globulin in the plasma. Therefore, the use of fish plasma is desired for the determination of fish plasma insulin.

\section{Deviation of $B / T$ Ratios of Skipjack Insulin at Various Levels}

The $B / T$ ratios of standard skipjack insulin at the various levels were determined seven times by the modified method. The deviation of $B / T$ ratios

Table 2. Variation of $B / T$ ratios at red sea bream and skipjack insulin levels when anti-skipjack insulin serum was used

\begin{tabular}{lccccccc}
\hline Insulin $(\mu \mathrm{U} / \mathrm{m} l)$ & & 0 & 3.9 & 7.8 & 15.6 & 31.2 & 62.5 \\
\hline Red sea bream & 1 & 43.5 & 41.0 & 40.1 & 33.9 & 26.8 & 20.0 \\
insulin & 2 & 48.0 & 46.1 & 43.7 & 38.2 & 33.0 & 25.5 \\
& 3 & 51.2 & 46.8 & 43.1 & 39.5 & 34.6 & 27.7 \\
& 4 & 46.1 & 43.3 & 41.5 & 35.7 & 30.2 & 24.3 \\
& 5 & 46.5 & 43.2 & 42.0 & 37.1 & 30.6 & 25.3 \\
\cline { 2 - 7 } & Mean & 47.1 & 44.1 & 42.1 & 36.9 & 31.0 & 24.6 \\
Skipjack & \pm SD & \pm 2.8 & \pm 2.3 & \pm 1.4 & \pm 2.2 & \pm 3.0 & \pm 2.8 \\
insulin & 1 & 44.7 & 39.6 & 39.0 & 33.3 & 24.0 & 19.3 \\
& 2 & 48.6 & 46.4 & 43.8 & 36.3 & 31.1 & 21.6 \\
& 3 & 50.0 & 45.4 & 41.2 & 38.7 & 33.3 & 23.0 \\
& 4 & 47.3 & 44.2 & 41.3 & 34.5 & 28.6 & 21.9 \\
& 5 & 45.6 & 41.5 & 39.1 & 35.6 & 28.2 & 20.0 \\
\hline
\end{tabular}

Numbers are shown by $B / T$ ratio $(\%)$. 
Table 3. Variation of $B / T$ ratios at yellowtail and skipjack insulin levels when anti-skipjack insulin serum was used

\begin{tabular}{crrrrrrr}
\hline Insulin $(\mu \mathrm{U} / \mathrm{m} l)$ & & 0 & 3.9 & 7.8 & 15.6 & 31.2 & 62.5 \\
\hline $\begin{array}{c}\text { Yellowtail } \\
\text { insulin }\end{array}$ & 1 & 42.9 & 44.1 & 39.7 & 34.9 & 29.7 & 22.8 \\
& 2 & 48.7 & 44.1 & 41.1 & 35.0 & 28.9 & 22.9 \\
\hline & Mean & 45.8 & 44.1 & 40.4 & 35.0 & 29.3 & 22.9 \\
\hline Skipjack & 1 & 43.8 & 39.3 & 38.4 & 33.1 & 22.3 & 18.8 \\
$\quad$ insulin & 2 & 45.5 & 39.8 & 39.6 & 33.4 & 25.7 & 19.8 \\
& Mean & 44.7 & 39.6 & 39.0 & 33.3 & 24.0 & 19.3 \\
\hline
\end{tabular}

Numbers are shown by $B / T$ ratio $(\%)$.

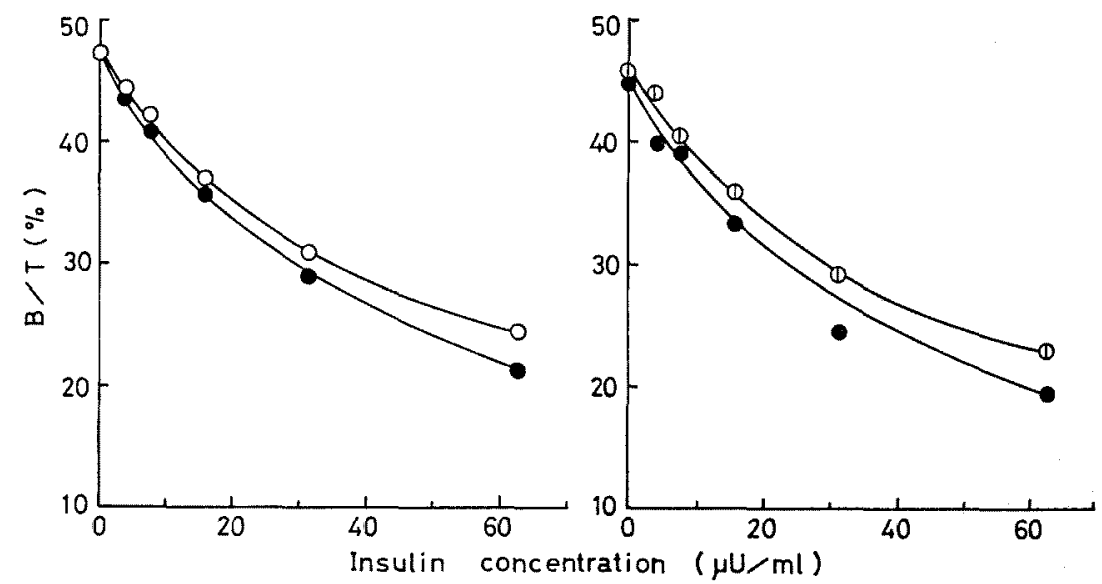

Fig. 2. Change in $B / T$ ratios of red sea bream, yellowtail, and skipjack insulin levels when antiskipjack insulin serüm was used.

$\bigcirc$ Red sea bream insulin, (1) Yellowtail insulin, $\odot$ Skipjack insulin.

Table 4. Variation of $B / T$ ratio at various levels of skipjack insulin

\begin{tabular}{cccccccc}
\hline \hline $\begin{array}{c}\text { Insulin } \\
(\mu \mathrm{U} / \mathrm{m} l)\end{array}$ & 0 & 3.9 & 7.8 & 15.6 & 31.2 & 62.5 & 125 \\
\hline 1 & 27.3 & 26.3 & 23.8 & 19.6 & 14.8 & 10.5 & 7.6 \\
2 & 30.2 & 26.3 & 25.8 & 22.7 & 18.7 & 13.9 & 9.0 \\
3 & 34.2 & 31.2 & 28.6 & 25.9 & 22.4 & 16.0 & 11.0 \\
4 & 30.7 & 28.2 & 26.3 & 23.7 & 19.8 & 15.3 & 10.6 \\
5 & 33.0 & 29.9 & 27.2 & 23.7 & 20.5 & 15.5 & 10.4 \\
6 & 33.9 & 31.0 & 29.0 & 24.8 & 20.2 & 15.2 & 10.7 \\
7 & 35.7 & 32.1 & 28.6 & 25.0 & 20.4 & 15.7 & 11.5 \\
\hline Mean \pm SD & $32.1 \pm 2.9$ & $29.3 \pm 2.4$ & $27.0 \pm 1.9$ & $23.6 \pm 2.1$ & $19.5 \pm 2.4$ & $14.6 \pm 1.9$ & $10.1 \pm 1.4$ \\
\hline
\end{tabular}

was very small at every insulin level (Table 4).

\section{Recovery Test}

A recovery test of red sea bream insulin was conducted by adding the known concentration of it into the blood plasma of red sea bream. As shown in Table 5, recovery values of red sea bream insulin ranged from $78.6 \%$ to $92.3 \%$. This recovery percentage, however, declined with increas- ing levels of insulin. Accordingly, if the sample contains a large amount of insulin, it should be diluted to less than $50 \mu \mathrm{U} / \mathrm{m} l$ insulin level with the veronal buffer in the assay.

The results of the present study made it clear that this modified method can be applied to determine the insulin content in blood plasma of fishes. 


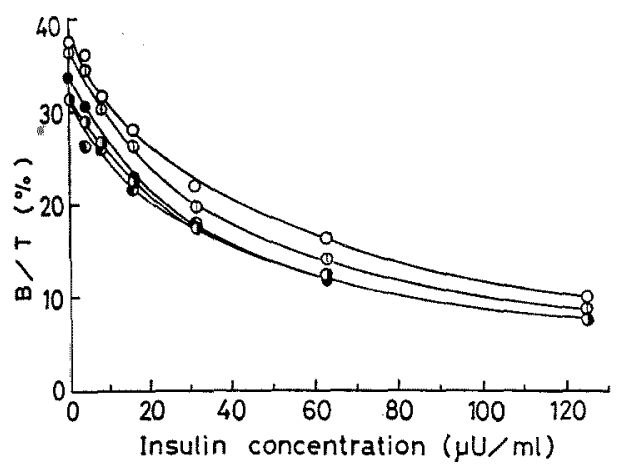

Fig. 3. Standard curve of skipjack insulin when human, red sea bream, yellowtail, and carp plasmas were used.

Human plasma, (1) Human palsama diluted 1:2, O Red sea bream plasma, O Yellowtail plasma, Carp plasma.

\section{Acknowlegement}

We are indebted to Mr. Y. KoHGA of Shimizu Seiyaku Co. Ltd., for kindly supplying the fish insulins.

\section{References}

1) M. Furuichi and Y. Yone: Bull. Japan. Soc.
Table 5. Recovery of red sea bream insulin added into blood plasma*1

\begin{tabular}{cccc}
\hline $\begin{array}{c}\text { Insulin } \\
\text { added } \\
(\mu \mathrm{U} / \mathrm{m} l)\end{array}$ & $\begin{array}{c}\text { Assay } \\
\text { value } \\
(\mu \mathrm{U} / \mathrm{m} l)\end{array}$ & \multicolumn{2}{c}{ Recovery } \\
\hline 0 & $18 \mathrm{U} / \mathrm{m} l)$ & $(\%)$ \\
3.9 & 22.1 & - & - \\
15.6 & 32.5 & 3.6 & 92.3 \\
31.2 & 45.4 & 14.0 & 89.7 \\
62.5 & 67.7 & 49.2 & 86.2 \\
\hline
\end{tabular}

*1 Red sea bream.

*2 Insulin content in blood plasma (blank).

Sci. Fish., 46, 225-229 (1980).

2) R.S. YALOW and S. A. Berson: J. Clin. Invest., 39, 1157-1175 (1960).

3) Y. Nakamura, Y. Hirata, H. Nishimura, and M. Fuzisawa: J. Japan. Diabetic Soc., 15, 1823 (1972).

4) R. S. Yalow and S. A. Berson: New Eng. J. Med., 270, 1171-1178 (1964).

5) S. FALKMER and S. WILson: Diabetologia, 3, 519-528, (1967).

6) K. Onoe: J. Japan. Diabetic Soc., 12, 250-258 (1969).

7) H. SANDo, Y. KanAzAwa, and T. KuzuYa: $J$. Japan. Diabetic Soc., 12, 291-295 (1969). 